\title{
A Comparative Study on Korean and Myanmar Personal Pronouns*
}

\author{
Myat Thida Oo \\ Yangon University of Foreign Languages, Yangon, Myanmar
}

\begin{abstract}
The purpose of this paper is to examine the similarities and differences between pronouns in Korean and Myanmar. In other words, we try to help Korean and Myanmar learners to study personal pronouns by comparing the personal pronouns between the two languages. Personal pronouns are used in Myanmar as "pronouns referring to people” as in Korean. The two languages are divided into first person, second person, and third person pronoun. However, looking at functions and usage, there seem to be many differences between the two languages. For example, in the case of Myanmar language, personal pronouns are different according to gender and personal pronouns are used differently for general people and monks. Myanmar also uses the personal pronouns differently depending on colloquial and written language. In the case of Korean language, there is no big difference between the sexes in different languages but there is difference between the people and monks in terms of Myanmar language. However, Korean people have difficulties in learning personal pronouns because their usage differs according to their status and social status. Therefore, in order to solve this problem, it is meaningful to identify commonalities and differences between languages by comparing characteristics and use of personal pronouns between the two languages.
\end{abstract}

Keywords: comparative study, commonalities and differences, functions, usage, social status

\section{Introduction}

The Korean pronoun is written as "a substitute for the name of an object”. In other words, pronouns appear in place of nouns, so the meaning is supposed to be a substitute word. And there are many kinds of pronouns in Korean and learners have difficulties in learning them. For example, in Korean, when referring to someone's mother, she is called "our mother". However, in Myanmar, this is called "my mother". I do not know why I should write a common "our" when I called my mother. Therefore, it is difficult to understand the personal pronoun of Korean. The purpose of this article is to examine the concepts and features of Korean and Myanmar personal pronouns and to find commonalities and differences between the two languages so that Myanmar learners can more easily access them when they learn Korean personal pronouns.

\section{Aim of the study}

This study aimed at discovering the similarities and differences of the personal pronouns in Korean and Myanmar.

\footnotetext{
* This paper was presented at the 2nd Korean Language Education Conference held in Myanmar. Myat Thida Oo, Assistant Lecturer, Ph.D., Korean Department, Yangon University of Foreign Languages.
} 


\section{Methodology}

In this chapter, we first examine the concept and kind of Korean pronouns and examine the concepts and types of pronouns in Myanmar. The concept and type of personal pronoun between Korean and Myanmar will be examined with the focus on the subject's pronoun. Furthermore, the author will examine the characteristics of the personal pronouns between the two languages and examine the common points and differences between them.

\section{Theoretical Concepts of Pronouns in Korean and Myanmar}

\section{Concepts and Types of Korean Pronouns ${ }^{1}$}

The pronoun in Korean is defined as "a word replacing the name of an object". Pronouns appear on behalf of nouns in place of nouns, so the meaning is taken on the premise that they can be replaced. The characteristics of the pronoun are as follows.

(1) Pronouns are basic characteristics of situation indication.

Example (1): a. 너는 거기서 무엇을 하고 있니?

(What are you doing there?)

b. 일행은 사평 역에서 내렸다. 거기서부터 마을까지는 걸어가기로 했다.

(The party got off at Sapyong station. From there I decided to walk to the village.)

“너” (you), “거기” (there), and “무엇” (what) of the example Sentence (1) cannot know what specifically indicates what is not given the proper situation. The pronoun becomes clear when the proper context is identified, such as "there" in the example Sentence (1).

(2) Pronouns do not give a name to an object, but instead refer to it in place of the name of an object, so it is possible to direct the form of the pronoun to the same thing.

(3) Nouns sometimes find features that are not well understood, such as form and function. For example, “나가” (I) and "너가” (you) appear as "내가” (I) and "네가” (you), but these characteristics are not found well in nouns. Also, “나” (I) or “너” (you) may change into “저” (I/me) or “자네” (you) depending on the status of the other person.

There are two types of pronouns: (1) person pronouns (first person, second person, third person pronoun) and (2) direction pronoun (object and place indication directive pronoun). Here, it is also based on the closeness between the speaker and the listener. Then the pronoun can be divided according to the status of the other party, or singular and plural.

\section{Concepts and Types of Myanmar Pronouns ${ }^{2}$}

The Myanmar pronoun is defined as a "substitute for noun". In other words, the noun can be substituted for the noun in place of the noun. There are four types in Myanmar as follows:

(1) Personal pronouns (first person, second person, third person pronoun);

(2) Direct pronouns (pronouns of things and places);

(3) Question pronouns (pronouns showing questions);

(4) Number pronouns (pronouns that show numbers).

The characteristics of pronoun Myanmar can be seen as follows.

\footnotetext{
${ }^{1}$ Quoted from Goyeong Geun. Gu Boungwan (2008).

2 Quoted from Myanmar Language Commission (2005).
} 
(1) Pronouns are basic characteristics of situation indication.

Example (2): a. thuthi ahtetan kyaungthar pyit thi

(He is high school student.)

b. nin akhu bar lote nay lel

(What are you doing now?)

c. Maung Hla thi Yangon to twer thi. Hto hma tasint Pegu to kayisetme

(Maung Hla is going to Yangon. Then he will go to Pegu.)

In the Example (2) "thu”, "bar", and "hto" cannot tell what specifically they refer to unless the appropriate situation is given. The pronoun becomes clear when the proper context, such as "there" of the example Sentence (2), is grasped.

(2) Pronouns do not give a name to an object, but instead refer to it in place of the name of an object, so it is possible to direct the form of the pronoun to the same thing.

(3) Pronouns "nga" (I) or "nin" (you) may change according to the status of the other person, or "kyanaw" or "kyama" depending on my intimacy with the other person. Depending on whether they are male or female, the form of the pronoun may change. And it can be written in different pronoun forms depending on the written language and the colloquial language.

\section{Personal Pronouns Contrast Between Korean and Myanmar}

\section{Characteristics of Korean Personal Pronouns}

Korean personal pronouns are pronouns referring to people, sometimes referring to as "ligature noun" or “person's main denomination”.

Example (3): a. 나, 저.

b. 우리, 저희.

Example (4): a. 너, 자네, 당신, 그대.

b. 너희.

Example (5): 이이, 이애, 이분; 그, 그이, 그애, 그분; 저이, 저애, 저분.

Examples (3-5) are relatively common personal pronouns. Example (3) is the first person pronoun: (3a) is singular and (3b) is plural. Example (4) is the second person pronoun: (4a) is singular and (4b) is plural. Example (5) is a third person pronoun, which is divided into root, middle, and original names. The usual way of expressing the plural of the Korean pronoun is to attach the suffix "-s". The personal pronouns in Korean are shown in the following table (see Table 1).

Table 1

Korean Personal Pronouns ${ }^{3}$

\begin{tabular}{|c|c|c|c|c|}
\hline \multirow{8}{*}{ Personal pronouns } & \multirow{3}{*}{ 1st person pronoun } & \multicolumn{2}{|r|}{ Singular } & \multirow{2}{*}{\begin{tabular}{|l|} 
Plural \\
우리
\end{tabular}} \\
\hline & & informal & 나 & \\
\hline & & formal & 저 & 저희 \\
\hline & \multirow{3}{*}{ 2nd person pronoun } & & Singular & Plural \\
\hline & & informal & 너 & 너희 \\
\hline & & formal & 자네, 당신, 그대 & 여러분 \\
\hline & \multirow{2}{*}{ 3rd person pronoun } & Direction (here) & Direction (there) & Direction (over there) \\
\hline & & 이이, 이애, 이분 & 그, 그이, 그애, 그분 & 저이, 저애, 저분 \\
\hline
\end{tabular}

${ }^{3}$ Quoted from Goyeong Geun. Gu Boungwan (2008, p. 70). 
The characteristics of Korean personal pronouns can be seen as follows:

(1) Characteristics of personal pronouns:

Example (6): a. *할아버지, 당신이 좀 도와주십시오.

(Grandpa, can you help me?)

b. 어르신께서 좀 도와주십시오.

(Can you help me?)

“당신” (you) must be more public than "너” (you), but as you can see in (6a) If you do not know the second person pronoun "당신" (you), you can get a protest saying "Why?". It is natural to use the "elderly", which can be regarded as a general noun rather than a pronoun, in the place where the "합쇼체” (polite usage) should be written. "그대" (you) can only be used in environments where literary works such as literary works and letters are used, but it is not used well in colloquial environments.

(2) Characteristics of personal pronouns:

There is an interesting phenomenon related to plural expression of pronoun by "-s". First of all, there is a phenomenon of using “우리” (we), “저희” (we), “너희” (you) by adding “들” to the plurals. Because it is common to attach "들" to express the plural of pronoun, it seems to be a phenomenon that is attracted to it. Only “그” (him) among "this”, "him”, "me” is used as a pronoun of person singular. However, it is also unique that the "-들" can be used as a plural pronoun, as well as “그들” (them: near direction), "이들” (them: nearest direction), and “저들" (others: furthest direction).

(3) Characteristics of personal pronouns:

“우리” (our) includes both the speaker and listener and is also used to exclude third parties.

Example (7): 우리 모두 힘을 합쳐 살기 좋은 나라를 만듭시다.

(Let's make a country where all of us can join together to live.)

In the example Sentence (7), “우리” (our: third person pronoun) includes the plural of not only the first person pronoun but also the second person. It is difficult to use "저희" (our: first person pronoun) in this case because it contains a listener because it is a jargon that lowers itself against the other. It is also related to the fact that “우리 나라” (our country) is natural and “저희 나라” (our country) is awkward. “우리” (our) may also appear in situations where singular writing is required. Especially, it is a natural phenomenon that "우리” (our) is used instead of "내” (my) and "나의” (my) when expressing ownership or belonging of an individual. I think this is because I did not think of family or country as an ownership but shared with other family.

\section{Characteristics of Pronouns in Myanmar}

Myanmar pronoun is defined as "a person's substitute word”. Personal pronouns are as follows: (1) first person (speaker), (2) second person (audience personality), and (3) third person (third person personality).

Example (8): a. nga (I: informal), kyanaw(I: male), kyama (I: female), tapyaetaw (I: male layman), tapyaetawma (I: female laywoman)

b. ngato (we: informal plural), kyanawto (we: male plural), kyamato (we: female plural), tapyaetawto (we: laymen), tapyaetawmato (we: laywomen)

Example (9): a. nin (you: informal), min (you: male), shin (you: female), dakarkyi (you: Monk addresses layman), dakarmakyi (you: Monk addresses laywoman)

b. ninto (you: informal plural), minto (you: male plural), shinto (you: female plural), dakarkyito (you: Monk addresses laymen), dakarmakyito (you: Monk addresses laywomen) 
Example (10): dilu (this man), holu (that man), ho:kalu (that man)

Examples (8-10) are relatively common personal pronouns. Example (8) is the first person pronoun: (8a) is singular and (8b) is plural. Example (9) is a second-person pronoun: (9a) is singular and (9b) is plural. Example (10) is a third person pronoun, which is divided into root, middle, and original names. Myanmar personal pronouns can be seen in the following table (see Table 2).

Table 2

Myanmar Personal Pronouns ${ }^{4}$

\begin{tabular}{|c|c|c|c|c|}
\hline & & & ngular & Plural \\
\hline & & informal & nga & ngato \\
\hline & 1st person pronoun & formal & $\begin{array}{l}\text { kyanaw } \\
\text { kyama } \\
\text { tapayetaw } \\
\text { tapayetawma } \\
\end{array}$ & $\begin{array}{l}\text { kyanawto } \\
\text { kyamato } \\
\text { tapayetawto tapayetawmato }\end{array}$ \\
\hline & & & ngular & Plural \\
\hline Personal pronouns & 2nd person pronoun & informal & $\begin{array}{l}\operatorname{nin} \\
\operatorname{nin}\end{array}$ & $\begin{array}{l}\text { ninto } \\
\text { thido } \\
\text { dakarkyito } \\
\text { dakarmakyito } \\
\end{array}$ \\
\hline & & formal & $\begin{array}{l}\text { min/ kamya: } \\
\text { shin }\end{array}$ & $\begin{array}{l}\text { minto/ kamya:to } \\
\text { shito }\end{array}$ \\
\hline & & Direction (here) & Direction (there) & Direction (over there) \\
\hline & 3rd person pronoun & dilu & holu & ho:kalu \\
\hline & & thu & thu/thuma & \\
\hline
\end{tabular}

The characteristics of Myanmar personal pronouns can be seen as follows:

(1) Characteristics of personal pronouns:

Example (11): a. MaungMuang thi kyaungto twerthi

(Maung Muang is going to school.)

b. thu thi ahtetankyaungthar: pyit thi

(He is high school student.)

Example (12): a. MoMo thi lainmathaw sin takaung pyit thi

(Mo Mo is a clever elephant.)

b. thu thi kyan ko alwan kyai?

(She likes sugarcane very much.)

In Example (11a), "Maung Maung" is "student (person)" and (11b) is a personal pronoun using "he" instead of "Maung Maung". However, in the example Sentence (12a), "Mo Mo" is the name of "elephant" and example Sentence (12b) is the personal pronoun used in place of "elephant". Most of them should be marked as "di sin” (elephant) or "ho sin” (elephant) and "ho:sin” (elephant) after " di, ho, ho: ”. However, in the example Sentence (12b), "thu” is used instead of "person". In other words, it can be seen that "thu”, which is used only for people, is also allowed to be used for animals.

${ }^{4}$ Quoted form Myanmar Language Commission (2005). 
(2) Characteristics of personal pronouns:

Example (13): a. Maung Zaw ko manayka ma twe bu

(Maung Zaw didn't see yesterday.)

b. thu nay ma kaung bu htin te

(He would be ill.)

Example (14): a. Ma Hla akhu hti ma la thay bu

(Ma Hla doesn't come yet.)

b. thu nauk kya mel htin te

(She will be late.)

In the Example (13a) above, "Maung Zaw" is "male" and the example Sentence (13b) uses the third person pronoun "thu" instead of "him". However, even in the example Sentence (14a), "Ma Hla" uses "thu", which is a pronoun of male third person. But in the example Sentence (14b), even though it is "female", Myanmar personal pronouns are distinguished according to their gender, but they are women here and they are unique in that they can be used as pronouns for a third man.

(3) Characteristics of personal pronouns:

Example (15): a. Maung Nyo thi alwan yain: thi

(Maung Nyo is very rude.)

b. thin ko tatihta:hu Maung Aye a: Daw Mya ka pyaw thi

(Daw Mya said be aware of him.)

Example (16): a. Mya Mya thi thu tapa: ko ku nyi lae shi thi

(Mya Mya helps the others.)

b. lekyang: ko lu tain:ka khinminkyathi

(People love her.)

Example (17): a. Maung Hla thi pya:naythi

(Maung Hla is ill.)

b. yin:ko sayawin ka saehto:paythi

(The doctor gives him a shot.)

The Example (15a) instead of "Maung Nyo", it is used as "thin", (16a) instead of "Mya Mya”, it is used as "lekaung:", and (17a) instead of "Maung Hla", it is used as "yin" as the third person pronoun. The example sentence (15b) originally used the third person pronoun "thu" in the case of man, where "thin" is available. However, "thin" used here can only be used in sentences showing negative emotions. Likewise, instead of "thu/thuma” in the example Sentence (16a), "lekaung:” is proposed. In this case, "yin" is mostly used in "directive pronoun: things". In the Example (17b) also "yin" is used as a third person pronoun. In common, the third person pronoun "thin, lekaung:, yin" seen in the example Sentences (15b, 16b, and 17b) seems to be used in the written language. 


\section{Common Features and Differences Between Korean and Myanmar Personal Pronouns}

In this chapter, we try to find out and compare the common points and differences between Korean and Myanmar personal pronouns. First, there are five common features of Korean and Myanmar personal pronouns. First, Korean and Myanmar personal pronouns refer to people. Second, Korean and Myanmar personal pronouns are classified into first, second, and third person. Third, Korean and Myanmar personal pronouns are plural and singular. Fourth, Korean and Myanmar personal pronouns seem to combine dependent nouns after nouns when making plural forms. Fifth, Korean and Myanmar personal pronouns have common "formal style" and "informal style".

There are three differences between the two. First, in Korean case, personal pronouns are not distinguished by sex, but in Myanmar case, personal pronouns are classified according to sex. Second, in Korean case, there is no personal pronoun in religion, but in Myanmar case, personal pronoun is divided according to religion. Second, in the case of Korean, religious personal pronouns are not distinguished, but in the case of Myanmar, personal pronouns are classified religiously. This is because the religion of Myanmar is Buddhism and it seems that the influence of Buddhism is reflected in the language. Third, in the case of Korean, "our", which is the personal pronoun, is a natural tendency to use "our" instead of "my" or "mine" when expressing ownership or belonging of an individual. It seems that Korea is the center of collectivism, therefore "our" prefers "my" and influences the language as a social aspect. However, in the case of Myanmar, the personal pronoun called "our" can be distinguished by being used only for common possessions. Finally, Korean personal pronouns are classified into "colloquial" and "written language", but in Myanmar, personal pronouns are divided into "colloquial" and "written language". Korean and Myanmar pronouns are presented in the following table (see Table 3).

Table 3

Common Features and Differences Between Korean and Myanmar

\begin{tabular}{|c|c|c|}
\hline & Korean & Myanmar \\
\hline Common & $\begin{array}{l}\text { (1) Korean personal pronouns refer to the person. } \\
\text { (2) Korean pronouns are divided into first person, } \\
\text { second person, and third person. } \\
\text { (3) Korean personal pronoun has singular and plural. } \\
\text { (4) Personal pronouns in Korean have a “들” behind } \\
\text { the noun and are attached to make a plural form. } \\
\text { (5) Korean pronoun has "informal style” and “formal } \\
\text { style”. }\end{array}$ & $\begin{array}{l}\text { (1) The Myanmar pronoun is used instead of noun. } \\
\text { (2) The Myanmar pronoun has three kinds of pronouns. } \\
\text { They are first, second, and third persons. } \\
\text { (3) The Myanmar pronoun has singular and plural. } \\
\text { (4) Personal pronouns in Myanmar add "tho" behind the } \\
\text { noun and to make plural form. }\end{array}$ \\
\hline Differences & $\begin{array}{l}\text { (1) Korean pronoun does not separated by gender. } \\
\text { (2) Korean personal pronouns do not have religious } \\
\text { personal pronouns. } \\
\text { (3) The Korean personal pronoun, “our", shows } \\
\text { possession or belonging instead of "my", and "our" is } \\
\text { a natural phenomenon. } \\
\text { (4) Korean personal pronouns are not distinguished } \\
\text { from "colloquial” and "written language”. }\end{array}$ & $\begin{array}{l}\text { (1) The Myanmar pronoun is divided into gender. } \\
\text { (2) Myanmar personal pronouns are used differently for } \\
\text { religious person. } \\
\text { (3) The Myanmar personal pronouns are } \\
\text { only for possessive nouns that do not have a common } \\
\text { meaning like "our". } \\
\text { 4) The Myanmar pronoun is distinguished as "spoken } \\
\text { language” and "written language”. }\end{array}$ \\
\hline
\end{tabular}

\section{Conclusion}

In this paper, we first look at the concepts of Korean and Myanmar personal pronouns and examine the types of personal pronouns between languages. And the author looked at the characteristics of personal pronouns between the two languages. Based on this, we have examined the similarities and differences between 
Korean and Myanmar personal pronouns. As a result, we saw that Korean and Myanmar pronouns have much in common. What is unusual is that we can get a glimpse of social aspects through personal pronouns between the two languages. For example, in Korean, "our” is a personal pronoun that shows Korean collectivism. In the case of Myanmar, "personal pronoun is distinguished when talking to a monk"

\section{References}

An, J. K., \& Eun, H. Y. (2006). A contrastive study of Korean and English Demonstratives Pronoun. The Journal of English, 35, 229-249.

Iee, I. S. et al. (1997). Korean Language. Shingu munhwasa.

Iee, I. S., \& Chae, W. (2000). Korean Grammar Lecture. Hag-Yeonsa.

Jang, H. S. (2008). A Study on the meaning of "amu+noun+ -ina" and "interrogative proun + -deunji”. The Journal of Korean language, 31, 69-90.

Jung, H. J. (2000). The research of Korean Noun. Hangu munhwasa.

Kim, K. S. (2015). A contrastive study of personal pronouns between Modern Mongolian and Korean Language. Journal of Mongolian Studies, 40, 47-79.

Ko, Y. G., \& Ku, B. G. (2008). Korean Grammar. Jibmundang.

Myanmar Language Commission. (2003). High school grammar. Sarpay Bike Man.

Myanmar Language Commission. (2005). Myanmar grammar. Sarpay Bike Man.

Seo, J. H., \&. Kim, S. J. (2012). A reconsideration on the systematization of Korean Pronoun. The Journal of the Humanities, 65, $1-24$.

U Pe Maung Tin. (1965). Myanmar grammar \& usages. Sarpay Bike Man. 